${ }^{1}$ School of Nursing, Laurentian University, Sudbury, Ontario, Canada

${ }^{2}$ School of Health and Social Care, London South Bank University, London, UK

\section{Correspondence to:}

Dr Roberta Heale, School of Nursing, Laurentian University, Sudbury, ON P3E2C6, Canada; rheale@laurentian.ca

\title{
What is a case study?
}

\section{Roberta Heale, ${ }^{1}$ Alison Twycross ${ }^{2}$}

\section{What is it?}

Case study is a research methodology, typically seen in social and life sciences. There is no one definition of case study research. ${ }^{1}$ However, very simply... 'a case study can be defined as an intensive study about a person, a group of people or a unit, which is aimed to generalize over several units.' A case study has also been described as an intensive, systematic investigation of a single individual, group, community or some other unit in which the researcher examines in-depth data relating to several variables. ${ }^{2}$

Researchers describe how case studies examine complex phenomena in the natural setting to increase understanding of them. ${ }^{3}$ Indeed, Sandelowski ${ }^{5}$ suggests using case studies in research means that the holistic nature of nursing care can be addressed. Furthermore, when describing the steps undertaken while using a case study approach, this method of research allows the researcher to take a complex and broad topic, or phenomenon, and narrow it down into a manageable research question(s). By collecting qualitative or quantitative datasets about the phenomenon, the researcher gains a more in-depth insight into the phenomenon than would be obtained using only one type of data. This is illustrated in the examples provided at the end of this paper.

Often there are several similar cases to consider such as educational or social service programmes that are delivered from a number of locations. Although similar, they are complex and have unique features. In these circumstances, the evaluation of several, similar cases will provide a better answer to a research question than if only one case is examined, hence the multiple-case study. Stake asserts that the cases are grouped and viewed as one entity, called the quintain. ${ }^{6}$ 'We study what is similar and different about the cases to understand the quintain better. ${ }^{6}$

\section{Method}

The steps when using case study methodology are the same as for other types of research. ${ }^{6}$ The first step is defining the single case or identifying a group of similar cases that can then be incorporated into a multiple-case study. A search to determine what is known about the case(s) is typically conducted. This may include a review of the literature, grey literature, media, reports and more, which serves to establish a basic understanding of the cases and informs the development of research questions. Data in case studies are often, but not exclusively, qualitative in nature. In multiple-case studies, analysis within cases and across cases is conducted. Themes arise from the analyses and assertions about the cases as a whole, or the quintain, emerge. ${ }^{6}$

\section{Benefits and limitations of case studies}

If a researcher wants to study a specific phenomenon arising from a particular entity, then a single-case study is warranted and will allow for a in-depth understanding of the single phenomenon and, as discussed above, would involve collecting several different types of data. This is illustrated in example 1 below.

Using a multiple-case research study allows for a more in-depth understanding of the cases as a unit, through comparison of similarities and differences of the individual cases embedded within the quintain. Evidence arising from multiple-case studies is often stronger and more reliable than from single-case research. Multiple-case studies allow for more comprehensive exploration of research questions and theory development. ${ }^{6}$

Despite the advantages of case studies, there are limitations. The sheer volume of data is difficult to organise and data analysis and integration strategies need to be carefully thought through. There is also sometimes a temptation to veer away from the research focus. ${ }^{2}$ Reporting of findings from multiple-case research studies is also challenging at times, ${ }^{1}$ particularly in relation to the word limits for some journal papers.

\section{Examples of case studies}

\section{Example 1: nurses' paediatric pain management practices}

One of the authors of this paper (AT) has used a case study approach to explore nurses' paediatric pain management practices. This involved collecting several datasets:

1. Observational data to gain a picture about actual pain management practices.

2. Questionnaire data about nurses' knowledge about paediatric pain management practices and how well they felt they managed pain in children.

3. Questionnaire data about how critical nurses perceived pain management tasks to be.

These datasets were analysed separately and then compared $^{7-9}$ and demonstrated that nurses' level of theoretical did not impact on the quality of their pain management practices. ${ }^{7}$ Nor did individual nurse's perceptions of how critical a task was effect the likelihood of them carrying out this task in practice. ${ }^{8}$ There was also a difference in self-reported and observed practices ${ }^{9}$; actual (observed) practices did not confirm to best practice guidelines, whereas self-reported practices tended to.

\section{Example 2: quality of care for complex patients at Nurse Practitioner-Led Clinics (NPLCs)}

The other author of this paper (RH) has conducted a multiple-case study to determine the quality of care for patients with complex clinical presentations in NPLCs in Ontario, Canada. ${ }^{10}$ Five NPLCs served as individual cases that, together, represented the quatrain. Three types of data were collected including:

1. Review of documentation related to the NPLC model (media, annual reports, research articles, grey literature and regulatory legislation).

2. Interviews with nurse practitioners (NPs) practising at the five NPLCs to determine their perceptions of the impact of the NPLC model on the quality of care provided to patients with multimorbidity. 
3. Chart audits conducted at the five NPLCs to determine the extent to which evidence-based guidelines were followed for patients with diabetes and at least one other chronic condition.

The three sources of data collected from the five NPLCs were analysed and themes arose related to the quality of care for complex patients at NPLCs. The multiple-case study confirmed that nurse practitioners are the primary care providers at the NPLCs, and this positively impacts the quality of care for patients with multimorbidity. Healthcare policy, such as lack of an increase in salary for NPs for 10 years, has resulted in issues in recruitment and retention of NPs at NPLCs. This, along with insufficient resources in the communities where NPLCs are located and high patient vulnerability at NPLCs, have a negative impact on the quality of care. ${ }^{10}$

\section{Conclusion}

These examples illustrate how collecting data about a single case or multiple cases helps us to better understand the phenomenon in question. Case study methodology serves to provide a framework for evaluation and analysis of complex issues. It shines a light on the holistic nature of nursing practice and offers a perspective that informs improved patient care.

Competing interests None declared.

Provenance and peer review Commissioned; internally peer reviewed.
- Article author(s) (or their employer(s) unless otherwise stated in the text of the article) 2018. All rights reserved. No commercial use is permitted unless otherwise expressly granted.

\section{References}

1. Gustafsson J. Single case studies vs. multiple case studies: a comparative study (Thesis). Halmstad, Sweden: Halmstad University, 2017.

2. Woods NF, Calanzaro M. Nursing research: theory and practice. St Louis: Mosby, 1980.

3. Hamel J. Case study methods. Newbury Park: Sage, 1993.

4. Yin RK. Case study research: design and methods. 2nd edn. Thousand Oaks: Sage, 2003.

5. Sandelowski M. One is the liveliest number: the case orientation of qualitative research. Res Nurs Health 1996;19:525-9.

6. Stake R. Multiple case study analysis. New york: The Guildford Press, 2006.

7. Twycross A. What is the impact of theoretical knowledge on children's nurses' post-operative pain management practices? An exploratory study. Nurse Educ Today 2007;27:697-707.

8. Twycross A. Does the perceived importance of a pain management task affect the quality of children's nurses' post-operative pain management practices? J Clin Nurs 2008;17:3205-16.

9. Twycross A. Children's nurses' post-operative pain management practices: an observational study. Int J Nurs Stud 2007;44:869-81.

10. Heale R, James S, Garceau ML. A multiple-case study in nurse practitioner-led clinics: an exploration of the quality of care for patients with multimorbidity. Nurs Leadersh 2016;29:37-45. 